\title{
Blending of pressed vegetable oils from pomegranate seeds and soybean to increase functional lipids consume
}

\begin{abstract}
The main objective of this study was to develop an affordable bioactive food ingredient from a blend of pressed pomegranate seed oil (PSO) and soybean oil (SO) microencapsulated by spray drying. Compared to liquid oil blends, the microencapsulated powder presented higher oxidative stability $(42 \%)$ due to the effective protection of the carrier agents and higher antioxidant capacity (two-fold) due to the antioxidant characteristic of the applied carrier material, proving to be an adequate alternative to associate the pressed pomegranate and soybean oils.
\end{abstract}

Keywords: functional lipids, pomegranate seeds oil, soybean oil, microencapsulation
Volume 7 Issue 3 - 2018

\author{
Nina K Silva-James,' Regina I Nogueira, ${ }^{2}$ \\ Suely P Freitas' \\ 'Department of Chemical Engineering, Universidade Federal do \\ Rio de Janeiro, Brazil \\ ${ }^{2}$ Embrapa Agroindústria de Alimentos, Rio de Janeiro, Brazil
}

Correspondence: Suely Pereira Freitas, Department of Chemical Engineering, Escola de Química, Universidade Federal do Rio de Janeiro, Centro de Tecnologia, Av. Athos da Silveira Ramos, I 49 Bloco E, sala 209, CEP: 2 1941-909, RJ, Brazil, Email freitasp@eq.ufrj.br

Received: April 09, 2018 | Published: May 16, 2018
Abbreviations: PSO, pomegranate seed oil; SO, soybean oil; PA, punicic acid; CLnA, conjugated linolenic acid; PUFA, polyunsaturated fatty acid

\section{Introduction}

Nowadays, the byproduct of fruit industrialization has been recommended as a raw material to obtain new functional ingredients that contribute to sustainability in agribusiness. Pomegranate fruit processing discards up to $50 \%$ of the raw-fruit, of which $14 \%$ are seeds. ${ }^{1}$ Pomegranate seed oil (PSO) contains over $70 \%$ of a rare punicic acid (PA) in its fatty acid composition. PA, a conjugated linolenic acid (CLnA), presents anti-inflammatory properties, and has been commercialized despite its very high sensibility to oxidation and its high price. Due to its availability, and competitive price, soybean oil (SO) is the most consumed vegetable oil in Brazil, and the Brazilian soybean production is the second largest in the world. ${ }^{2}$ Thus, the PSO blend with a more stable and accessible oil, such as so, will contribute to the manufacture of a more stable product, extending its useful life. The blending of vegetable oils with different fatty acid profiles is a common practice to improve physical-chemical characteristics and achieve new industrial applications. ${ }^{3}$

\section{Objective}

The aim of the present study was to develop a microencapsulated food ingredient that increases CLnA intake by humans. For this purpose, the raw oils were characterized with regard to their fatty acid composition, total phenolic compounds, antioxidant capacity and oxidative stability. Maltodextrin and gum Arabic (1:1) was used to assess the influence of different drying temperatures $\left(110^{\circ} \mathrm{C}\right.$ to $\left.150^{\circ} \mathrm{C}\right)$ on oxidative stability, antioxidant capacity and structure of powder.

\section{Materials}

Fresh pomegranate (Punica granatum) fruits, growing in the semiarid Brazilian region, were purchased directly from a farm. Cold-pressed soybean organic ${ }^{\circledR}$ oil was acquired from a local product store. This oil had no added antioxidants, as declared by the supplier. Maltodextrin DE 5 (MD, Globe ${ }^{\circledR}$ 1805) and Gum Arabic (GA, Vetec) were purchased in Brazil.

\section{Processing}

The oil blends were prepared by adding PSO to SO at a 1:4 ratio $(w / w)$ followed by mixing in an Ultra-Turrax IKA, for 2 minutes. An oil:carrier material ratio of 1:4 was applied. The emulsion was prepared by continuously adding the carrier materials dispersed in water to the blend, reaching $30 \%$ of total solid contents for all emulsions, as recommended by $\mathrm{Li}$ et al. ${ }^{4}$ The microencapsulation was performed using a mini-spray dryer (LabPlant SD-06). The emulsion was fed at $0.36 \mathrm{~L} \cdot \mathrm{h}^{-1}$, with a co-current air flow rate of $25 \mathrm{~kg} . \mathrm{h}^{-1}$ and air inlet temperature between $110^{\circ} \mathrm{C}$ and $150^{\circ} \mathrm{C}$, using a $0.7 \mathrm{~mm}$ diameter nozzle. The room temperature was maintained at $25 \pm 0.5^{\circ} \mathrm{C}$ and relative air humidity in about $40 \%$. The powder was stored into sealed metallic packaging at $-18^{\circ} \mathrm{C}$.

\section{Analytical methods}

Fatty acid was evaluated $a$ ccording AOCS official method (Ce $1 \mathrm{j}-07){ }^{5}$ total phenolic compounds was carried out according to Nascimento et al. ${ }^{6}$ oxidative stability was measured on a Rancimat ${ }^{\mathbb{R}}$ 743 equipment according to the EN 14112 accelerated test, at $80^{\circ} \mathrm{C}$, as recommended by Lutterodt et al. ${ }^{7}$ antioxidant capacity was determined according DPPH (2,2-diphenyl-1-picryl-hidrazil) radical method, adapted for vegetable oils; the moisture content of the powder was determined according to the AOAC method $934.01 ;{ }^{8}$ surface free oil content was determined by successive washings in hexane according to Carneiro et al. ${ }^{9}$ the encapsulation efficiency was calculated as the ratio between the encapsulated oil and total oil content in the powder; the microphotographs were taken on a TM3030 plus Hitachi scanning electron microscopy (SEM), using an accelerating voltage of $15 \mathrm{kV}$ at 7000x magnification. All analytical determinations were carried out in triplicate and variance analysis (ANOVA) followed by Fisher's LSD test was performed using Statistica v.13.0. 


\section{Discussion and conclusion}

A new technology for pomegranate seed application was developed based on the microencapsulation of PSO:SO blend. The physicochemical characteristics of the microencapsulated product are mainly controlled by inlet air temperature, inlet air flow rate and encapsulating material composition. The selection of the carrier agent for wall material is critical, since it protects the core during heating and increases yield by reducing stickiness. The chosen combination of carrier materials was MD:GA, and it reached $95 \%$ of encapsulation efficiency at drying temperature of $130^{\circ} \mathrm{C}$ and air flow rate of $25 \mathrm{~kg} \cdot \mathrm{h}^{-1}$. In these conditions, the antioxidant capacity $(0.85 \mathrm{mg} /$ $\mu \mathrm{g}$ DPPH) and induction time (16 hours) of microencapsulated powder was, respectively, 2.5 -fold and $42 \%$ higher as compared to the non-encapsulated oils blend. The PSO:SO blend contains phenolic compounds, ellagic and p-hidroxibenzoic acid and morin, which have antioxidant capacity against free radicals. The antioxidant property of these extracts may protect lipids against oxidative rancidity and may be able to replace synthetic additives. In human metabolism, they may act in the prevention of oxidative-caused diseases, such as atherosclerosis and cancer. At a 500x and 7000x magnification, it was possible to observe rounded capsules, as shown in Figure 1, with smooth surfaces, indicating that the encapsulation process effectively created a physical protection to the core. Additionally, the microcapsules presented high content of MUFAs and PUFAs (about $80 \%$ ), including $15 \%$ of punicic acid ( $\omega-5)$, and it may be an adequate source of ingredients for food or pharmaceutical industries.

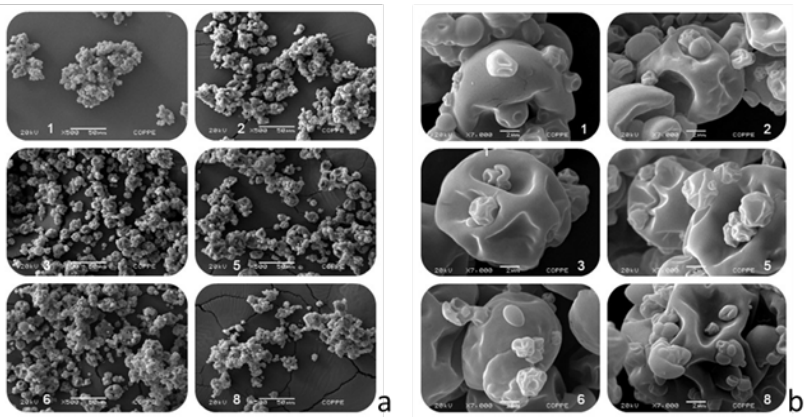

Figure I SEM micrographs of microcapsules: Magnification (A) 500x and (B) 7000x.

\section{Acknowledgements}

None.

\section{Conflict of interest}

The author declares no conflict of interest.

\section{References}

1. Goula AM, Lazarides HN. Integrated processes can turn industrial food waste into valuable food by-products and/or ingredients: The cases of olive mill and pomegranate wastes. Journal of Food Engineering. 2015;167:4550.

2. World Agricultural Supply and Demand Estimates. USDA; 2017

3. Hashempour-Baltork F, Torbati M, Azadmard-Damirchi S, et al. Vegetable oil blending: A review of physicochemical, nutritional and health effects. Trends Food Science Technology. 2016;57:52-58.

4. Li J, Xiong S, Wang F, et al, Optimization of Microencapsulation of Fish Oil with Gum Arabic/Casein/Beta-Cyclodextrin Mixtures by Spray Drying. J Food Sci. 2015;80(7):C1445-C1452.

5. Official methods and recommended practices of AOAC. AOAC International; 2013.

6. Nascimento L, Santiago M, Oliveira E, et al. Characterization of Bioactive Compounds in Eugenia brasiliensis, Lam. Nutritional Food Technology. 2017;3:1-7.

7. Lutterodt H, Slavin M, Whent M, et al. Fatty acid composition, oxidative stability, antioxidant and antiproliferative properties of selected coldpressed grape seed oils and flours. Food Chemistry. 2011;128(2):391-399.

8. Official Methods of Analysis of AOAC International.18th ed. USA: AOAC Press; 2005.

9. Carneiro HCF, Tonon RV, Grosso, et al. Encapsulation efficiency and oxidative stability of flaxseed oil microencapsulated by spray drying using different combinations of wall materials. Journal of Food Engineering. 2013;115(4):443-451. 